\title{
Journal of Rubber Research at 90
}

\author{
Veronica Charlotte ${ }^{1}$
}

Published online: 17 February 2020

(c) The Malaysian Rubber Board 2020

Journal of Rubber Research $90^{\text {th }}$ Anniversary:

An Evolution from $1929-2019$
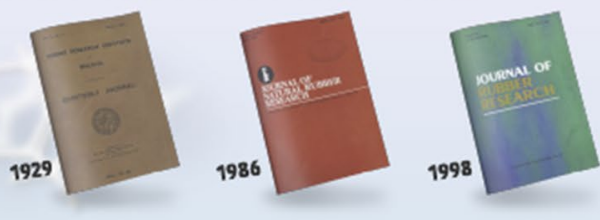

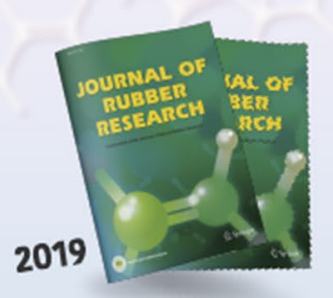

New in 2019:

Volume 22 now published with Springer

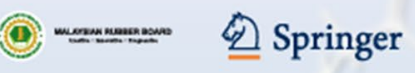

Evolution of JRR from its initial publication in 1929 up to 2019

Since its maiden issue was published, Journal of Rubber Research (JRR) has evolved alongside the research community it serves and we hope to grow towards impactful scholarly recognition in the years to come. The first issue, then Journal of the Rubber Research Institute of Malaya was published in 1929 and in 2019, the Journal of Rubber Research advanced into its first online Volume 22, as a result of a publishing partnership with Springer Nature, marking 90 years since the official start of this publication of the Malaysian Rubber Board.

The 4th iteration of JRR has been redesigned to allow for optimal communication of research findings to serve researchers worldwide and disseminate scientific knowledge in this digital age. This new design enhances the dynamic platform where readers now access current volumes (https:// www.springer.com/journal/42464), apart from the appealing printed version and digitized backfiles (rios.lgm.gov.my), accordingly. In a continuous effort to communicate science clearly, authentically and accurately, our content has always been changing with the times, largely influenced by advances in rubber sciences and publishing technology.

Veronica Charlotte

veronica@lgm.gov.my

1 Kuala Lumpur, Malaysia
JRR publishes original research and authoritative reviews across a broad ranging context of multidisciplinary rubber science categories encompassing core disciplines of bioscience, chemistry and technology. In these 90 years, JRR has published a total of 1,337 research articles (RAs) of which 737 are categorised under biosciences and 600 on chemistry and technology related research. RAs under the biosciences category comprise subcategories of crop improvement (breeding and selection, tissue culture or genetic transformation, genetic or molecular markers), crop protection (pathology, molecular pathology, pest, disease and weed control), agronomic practices (soil science, cover crops and beneficial microbes, fertilizer and plant nutrition, bud-grafting, field experiment design), plant structural parameters and latex harvesting (plant physiology and molecular analyses, anatomy and ultrastructure, latex harvesting practices) as well as studies on fresh latex (latex characterisation, rubber particle and molecule characterisation, latex proteins, allergens and genes).

Chemistry and technology RAs, on the other hand, are comprised of subcategories including rubber chemistry and technology (vulcanisation and crosslinking, degradation and ageing, filler reinforcement and interaction, modification, composites, polymerisation and synthesis, polymer colloids, adhesion and adhesives), rubber processing and technology (blends and mixing, nanocomposites and nanomaterials, 
rheology, processing, microstructure, properties of rubber, physical science, odour control, effluent and waste treatment), latex science and technology, rubber for engineering or construction applications, analytical chemistry and tyre technology.

The latest volume features impactful research articles published in every quarterly issue, including TEM observation of silane coupling agent in silica-filled rubber tyre compound (JRR Volume 22, Issue 1, https://doi.org/10.1007/ s42464-019-00005-y); International investigation of shear displacement capacity of various elastomeric seismicprotection isolators for buildings (JRR Volume 22, Issue 1, https://doi.org/10.1007/s42464-019-00006-x); Colloidal properties of precipitated calcium carbonate dispersion and its effect on prevulcanised natural rubber latex rheology and film tensile properties (JRR Volume 22, Issue 1, https://doi. org/10.1007/s42464-019-00009-8); The effect of damping in isolation system on the performance of base-isolated system (JRR Volume 22, Issue 2, https://doi.org/10.1007/s4246 4-019-00012-z); The effect of field natural rubber latex pretreatment with cationic exchange resin on latex dipped film properties (JRR Volume 22, Issue 2, https://doi.org/10.1007/ s42464-019-00015-w); and Urea as a single denaturing agent in deproteinisation of natural rubber latex (JRR Volume 22, Issue 2, https://doi.org/10.1007/s42464-019-00016 -9); An uncommon outbreak of irritant contact dermatitis caused by rubber accelerators: a historical cohort study (JRR Volume 22, Issue 3, https://doi.org/10.1007/s42464-01900023-w); Colloidal properties of epoxidized natural rubber latex prepared via membrane separation technology (JRR Volume 22, Issue 4, https://doi.org/10.1007/s42464-01900029-4); Utility of PacBio Iso-Seq for transcript and gene discovery in Hevea latex (JRR Volume 22, Issue 4,https:// doi.org/10.1007/s42464-019-00026-7); Optimisation of elastomeric bearings' vulcanisation process using response surface methodology and desirability function approach (JRR Volume 22, Issue 4, https://doi.org/10.1007/s4246 4-019-00027-6); and Thermal and crystallization behaviour of epoxidized high cis-polybutadiene rubber (JRR Volume 22, Issue 4, https://doi.org/10.1007/s42464-019-00028-5). In keeping with relevance and interests of the industry, RAs on economics and market exploratory findings are also gaining popularity, such as Comparative advantage and export performance of India's rubber sector: an exploratory analysis (JRR Volume 22, Issue 3, https://doi.org/10.1007/s4246 4-019-00,022-x).

Events to commemorate this major milestone for JRR as a publication of the Malaysian Rubber Board include a soft launch of the publishing partnership with SpringerNature in 2018 , as well as celebration of JRR's $90^{\text {th }}$ anniversary and a talk on Scientific Publishing in 2019, depicted in the images below. Looking forward, considering the importance of rubber-related research as a global endeavour which has proven to be increasingly collaborative over time, JRR aims to publish special issues and topical collections on advances in the rubber science domain from 2020 onwards.

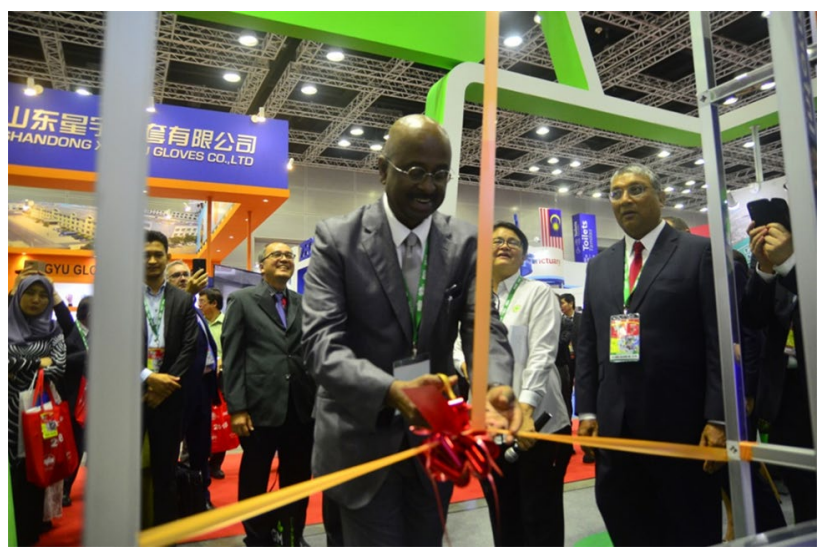

The publishing partnership was officiated by Datuk Sankara N Nair, Chairman of the Malaysian Rubber Board on 4 September 2018 at a soft launch event held during the International Rubber Conference 2018, in Kuala Lumpur

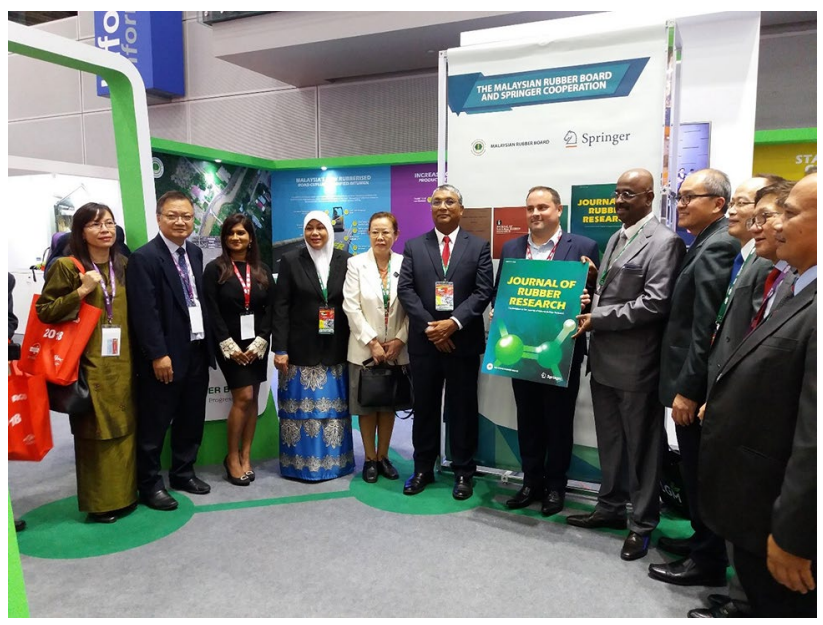

JRR Editorial Committee and Board Members graced the soft launch event 


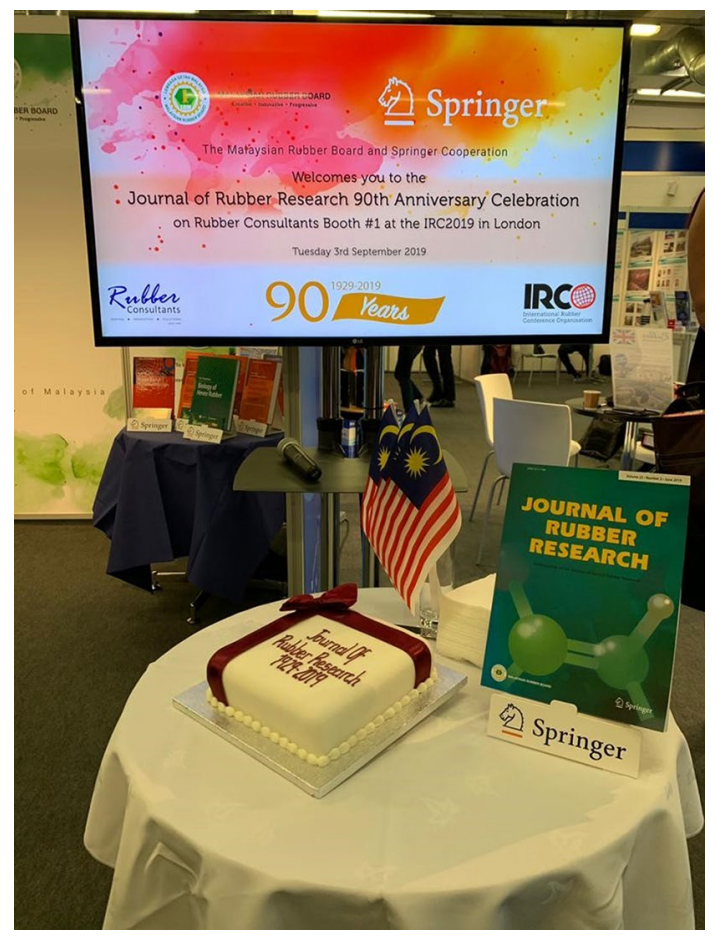

An event to commemorate the 90th Anniversary of JRR was held on 3 September 2019 in conjuction with the International Rubber Conference 2019, in London

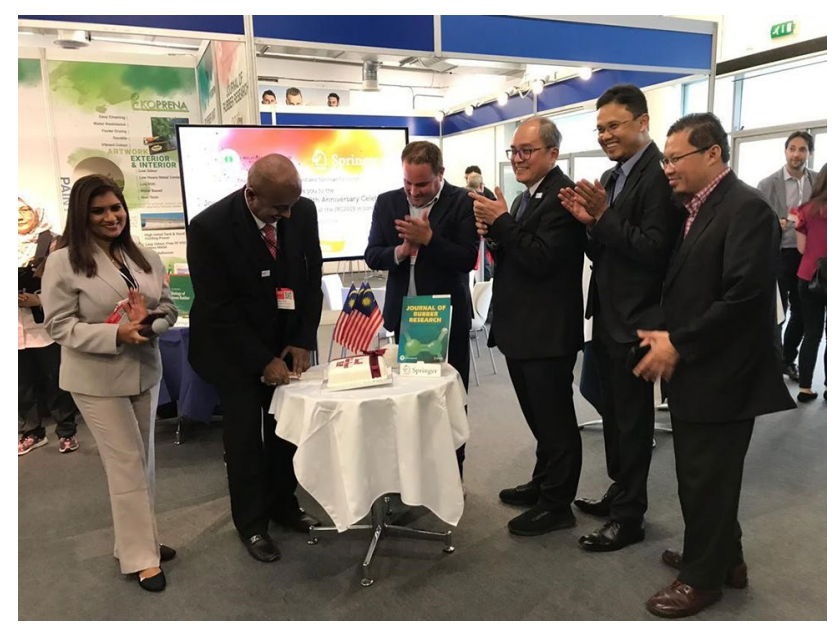

The anniversary event was officiated by MRB Chairman, Datuk Sankara N Nair, and graced by Dr Christoph Baumann, Editorial Director at SpringerNature based in Dordretch, the Netherlands, together with Directors of MRB, JRR Editorial Board Members and fellow distinguished guests

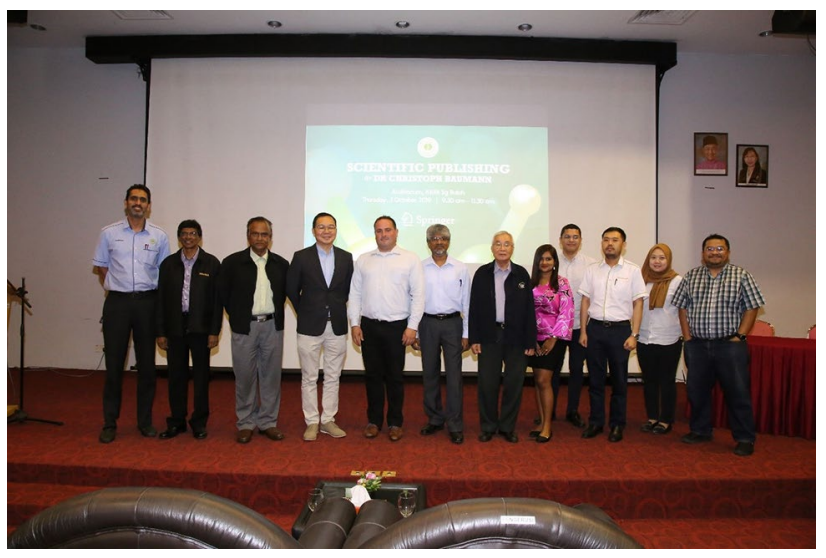

JRR Editors and industry representatives with the guest speaker, Dr Christoph Baumann

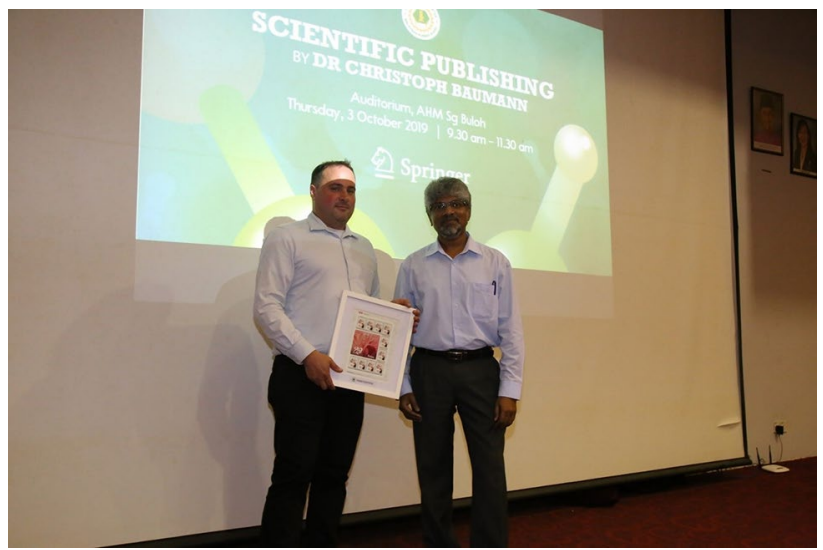

Dr Sunderasan E., presenting a token of appreciation to the guest speaker, on behalf of the MRB Management

Publisher's Note Springer Nature remains neutral with regard to jurisdictional claims in published maps and institutional affiliations. 